\title{
Subjetividade e "Deslocamento" na obra homônima de Lucy Knisley
}

\author{
Subjectivity and "displacement" \\ in Lucy Knisley's work
}

\begin{abstract}
In certain way, "displacement" refers to the change. It is the action of a body that moves from a certain space to another. In addition to its obvious physical implications, in the case of human displacement, there are also great subjective implications. In this way, displacement can be of other orders, as symbolic, metaphysical and mental, we can also consider even maturation as the displacement from one psychic state to another. In this case, the present work aims to analyze the different figurations of the concept of displacement present in the work: Displacement A travelogue by Lucy Knisley, as well as the affiliation of the work to a narrative tradition perpetrated by authors who take the daily genre and the trip report as a means of subjective construction of reality, both in literature and in comics. In order to do so, will be used authors who studied the writing of female authors, having the travel narrative as a research horizon, such as Sonia Serrano and Miriam Adelman; as well as authors who focus on the specificities of the comic language that, under the aegis of "graphic novel", engender an aesthetic construction that privileges the autobiographical narrative (Santiago Garcia and Hilarry Chute). We intend to highlight the richness that the comics bring to the symbolic construction of the genre "travel diary/narrative" through its peculiarities of self-representation.
\end{abstract}

Keywords: comics, subjectivity, travel narrative

A figura da mulher autora e da leitora, muito controversa na historiografia da literatura, sedimenta-se, por assim dizer, quando livro ganha sua forma impressa e se torna mercadoria. Com o advento da modernidade e a ampliação do entretenimento, peças-chave para a participação da mulher no meio editorial. No entanto, desde a década de 1940, com a publicação da obra O Segundo Sexo de Simone de Beauvoir, que levou os movimentos feministas a um novo patamar, muito tem sido discutido sobre a construção de uma identidade feminina que parte do social. Judith Butler (1987) postula que a construção dessa identida- 
de só pode ocorrer em relação direta com o social, acarretando uma série de determinismos sociais de teor biológico, histórico e outros que passam a ser afirmados. Já na segunda metade do século XX, a comunidade intelectual acirrará os questionamentos acerca da presença e do reconhecimento das mulheres no campo da literatura, libertando-as de seus nichos socialmente impostos por uma cultura patriarcal (como os romances de amor, ou com temas restritamente "do lar"). Mesmo hoje o debate ainda não se encerrou, o que vemos florescer desde meados do século XX, com uma intensificação a partir da década de 1980, são as histórias em quadrinhos feita por mulheres, que somada à literatura de autoria feminina, vem abrindo caminho e conquistando espaço dentro do mercado, atraindo a atenção dos leitores e da crítica especializada. Nessa seara, um gênero dos quadrinhos que vêm ganhando mais força com a contribuição das autoras é o gênero de quadrinhos autobiográficos. Destes, pinçamos um para analisarmos nesse artigo: Deslocamento: um diário de vagem de Lucy Knisley, um relato autobiográfico em quadrinhos.

A grosso modo, "deslocamento" diz respeito à mudança (de algo ou alguém) de um lugar para outro. É a ação de um corpo que se desloca de um determinado espaço para outro que, além de suas obvias implicações físicas, no caso do deslocamento humano, há também grandes implicações subjetivas. Podendo esse deslocamento ser de outras ordens, como simbólica, metafísica e mental, podemos também considerar o amadurecimento como o deslocamento de um certo estado psíquico para outro.

Se é certo que a viagem nasce da necessidade de, em concreto, nos deslocarmos de um ponto geográfica a outro, ela é vista essencialmente como algo interior, um reflexo da vida e das suas etapas.

Serrano, 2014, p. 17

Esse deslocamento pode não ser definitivo ou tão pouco definidor, mas com certeza é imperscrutável como um todo, e é isso que o torna fascinante, assim como nosso objeto de análise.

A norte-americana Lucy Knisley é uma jovem e solteira artista freelancer que, na altura dos seus 27 anos, decide embarcar em uma viagem, um cruzeiro de sete dias em alto-mar pelo Caribe, com seus avós paternos nonagenários. Casados há 67 anos, Phyllis e Allen decidem realizar esse sonho antigo e se inscrevem para embarcarem junto a um grupo da casa de convivência onde vivem, deixando a família em polvorosa.

A HQ, narrada em primeira pessoa, transcorre de forma linear, constituindo-se de relatos diários dessa viagem, detalhando sua relação de cuidados com os avós debilitados. Alternando momentos cômicos, tristes e por vezes trágicos que acentuam, muitas vezes, sua impotência diante da decadência mental e física de seus avós. Lucy confronta-se com reflexões a respeito da efemeridade da vida, e com o choque em vê-los tão fragilizados e dependentes, um contraste com as 
imagens da infância que guarda com carinho na memória. A autora traz em um tom coloquial e sincero, às agruras de seu deslocamento geográfico (Nova York/ Caribe), físico (terra/mar), psíquico (psicológico/comportamental) e subjetivo (banal/existencial). Suas experiências são descritas com delicadeza e bom humor capaz de temperar a angustia da proximidade da morte que a convivência com seus avós inevitavelmente traz, assumindo (descobrindo) o desconforto e a solidão de tal empreitada.

Todos os personagens são apresentados a partir do ponto de vista de Lucy e, como também se trata de um diário de relatos reais, a autora não ousa se aprofundar em suas naturezas psíquicas, resignando-se a relatar apenas momentos partilhados por sua protagonista e seus personagens secundários, que se resumem a seus familiares, transeuntes do cruzeiro, guichês de embarque, vizinhos de acento no avião, etc. Por mais que os contatos estabelecidos com esses personagens sejam aparentemente banais e corriqueiros, por vezes, esses momentos efêmeros em sua simplicidade suscitam alguma reflexão, acrescentando mais uma camada de subjetividade a personagem da própria Lucy.

Lucy Knisley, ao adotar o gênero diário, mesmo que um tipo específico, o diário de viagem, e uma forma mais especifica ainda: um diário de viagens em quadrinhos, autobiográfico por natureza, Lucy filia-se a uma tradição de relatos de mulheres viajantes: "O ímpeto de partir, a viagem realizada, une-as, a reflexão que sobre ela fazem e o testemunho que deixam também, mas a partir daí cada uma constrói a sua própria identidade" (Serrano, 2014, p. 26).

Diferentemente das viagens empreendidas pelo homem, geralmente de cunho exploratório/científico com ares de "conquista", muitas vezes exacerbado e fantástico, historicamente, as viagens empreendidas por mulheres apresentam relatos considerados mais íntimos e confessionais do que os provenientes das viagens masculinas (Serrano, 2014).

No século IV, começa um aumento do deslocamento de mulheres do Ocidente para o Oriente, muito impulsionadas pela imperatriz Helena de Constantinopla (250-330), mãe do imperador Constantino (Serrano, 2014, p. 96). Mas é de fato, somente com Egéria (século IV), que se tem o primeiro relato de viagem escrito por uma mulher, e o segundo do gênero, precedido apenas por um peregrino de Bordéus, que escreveu um testemunho de peregrinação 50 anos antes (Serrano, 2014, p. 97). Somente séculos depois é que essa prática, digamos, se "populariza", tendo como grandes representantes Lady Mary Wortley Montagu (1689-1762) e Ida Pfeiffer (1797-1858), chegando até às escritoras Beats como Elise Cowen (1933-1962), Hettie Jones (1934), Denise Levertov (1923-1997), Joyce Johnson (1935), e Diane di Prima (1934).

A personagem e a autora, Lucy, mesmo que ignore dentro e fora da diegese tal filiação, nos dá a perceber que, muito mais do que a empreitada, o gênero e o relato, todas essas mulheres tem em comum a construção de sua subjetividade, constituída não só pelo deslocamento, mas também pelas relações estabe- 
lecidas com o outro, no caso de Lucy, os avós, familiares e transeuntes que permeiam a narrativa. Essas relações, segundo Adelman (2009), tornam-se constitutivas do "sujeito moderno". Diferentemente de suas antecessoras, Lucy não faz uma "grande" viagem, não desbrava os mistérios do oriente, tampouco roda pelos Estados Unidos de carona como as escritoras Beat norte-americanas, sua empreitada é muito simples, porém não é simplória: acompanhar seus debilitados avós em um cruzeiro, com tudo pago, por sete dias. Há grandes chances de que essa seja a última viagem deles. Esse fim eminente, aliado a letargia do convívio em alto mar num navio repleto de idosos, faz com que sua viagem subjetiva seja muito mais desafiadora do que qualquer deslocamento físico.

Já no campo dos Quadrinhos, Deslocamento filia-se a uma certa tradição dos quadrinhos voltados ao um público mais maduro, a das chamadas graphic novels que, desde sua gênese, trazem narrativas autobiográficas. A historiografia dos quadrinhos tende a demarcar como ponto inicial dessa tradição a obra Um contrato com Deus (1978) de Will Eisner, que traz, como bem aponta Santiago Garcia:

Um dos traços que serão característicos dos quadrinhos alternativos e que se manterão como artéria principal da novela gráfica atual: a introdução da autobiografia, ou pelo menos da memória e dos elementos autobiográficos.

García, 2012, p. 26

Outra grande obra que surge nessa esteira é: Maus (1986), de Art Spigelman, ganhadora do prêmio Pulitzer, o que, de certa forma, deu uma chancela de reconhecimento ao gênero jornalístico/autobiográfico. Logo, as autoras de quadrinhos também começam a se destacar nesse nicho, produzindo grandes trabalhos, de relevância incontestável, como é o caso de Marjane Satrapi, como seu Persépolis (2007), e Alisson Bechdel, com a dobradinha Fun Home (2016) e o Você é minha mãe? (2013) seguidas de dezenas de outras autoras que apresentam trabalhos autobiográficos extremamente potentes, como Power Paola, Anne-Charlotte Gauthier, Julia Wertz, Dominique Goblet e Sirlanney, para citar algumas.

Deslocamento é, acima de tudo, uma jornada de autodescobrimento. Lucy exerce uma subjetividade reflexiva e sensível, capaz de deslocar o leitor para o lugar que a personagem ocupa, fazendo-o refletir acerca de como ele próprio se relaciona ou se relacionou com seus próprios familiares, levando-o a uma discussão pouco cômoda a respeito da decadência psíquica, da debilitação do corpo, e a da mortalidade, própria e a do outro. Lucy traz um olhar complacente para as questões rotineiras que, com seus avós beira o insuportável: Sua avó já está senil, e mal consegue se lembrar quem Lucy é, ou o que aconteceu na manhã do mesmo dia. Já o avô, por sua vez, não dá conta de sua própria higiene. A tentativa de compreendê-los, ao mesmo tempo em que lhes dá toda a assistência, e em contato direto com toda sua vulnerabilidade, expõe ao leitor todas as suas in- 
seguranças com relação a vida, ao futuro dos avós e seu próprio futuro. Olha-los é como olhar a um espelho que reflete o seu crepúsculo.

Fatos pregressos como a tentativa de superação de um termino de namoro também contaminam a história, acrescendo mais uma camada ao mosaico que vai se formando ao longo na narrativa que traz, além de suas questões pessoais de cunho afetivo, memórias de infância, sua relação com os demais membros da família e, a grande sacada da $\mathrm{HQ}$, que são os trechos do diário de seu avô, que Lucy (autora) intercala à narrativa principal, mas sem abrir mão de suas impressões e comentários espirituosos. Seu avô foi veterano da Segunda Guerra Mundial, e em certo momento da vida, escreve suas memórias, presenteando Lucy com uma cópia. O livro a acompanha por toda a viagem, sua intenção era que, ao lê-lo, pudesse compreender melhor aquele senhor teimoso, que molha as calças várias vezes e que fora, um dia, aquele avô carinhoso que lhe lançava ao ar quando menina. Os trechos do diário de seu avô se tornam uma Mise en abyme, em que seus relatos de guerra ecoam na própria batalha que Lucy enfrenta ao cuidar desse velho soldado. Por sua vez, a avó, que fora uma grande professora no passado, inspiração para o seu amor pela leitura, já não consegue mais dar conta de ler sequer algumas páginas. A distância que, de certa forma, já existia entre elas, se torna um abismo agravado pela velhice. Férias escolares, o cheirinho de café, as tardes preguiçosas vendo TV com o avô, toda essa memória sinestésica contamina toda a narrativa.

Considerações sobre a identidade e a subjetividade se configura como uma grande questão social de nosso tempo. Quadrinhos de autoria feminina como Deslocamento, vêm ganhando grande visibilidade e ampliando discussões e reflexões sobre a condição da mulher na sociedade contemporânea, e das muitas dificuldades e estigmas que precisam ser superados. Pode-se perceber facilmente a riqueza que as histórias em quadrinhos trazem para a construção de uma obra autobiográfica, seja pela característica naturalmente fragmentária dos quadrinhos que, de certa forma, emula o funcionamento da memória, possibilitando a convivência justaposta de temporalidades distintas em uma mesma página, ou num mesmo quadrinhos, ou por suas peculiaridades no que consiste a autorrepresentação, possibilitando às mulheres também uma dimensão visual de suas experiências.

Deslocamento é uma viagem de autoconhecimento, permeado por memórias e afetos, angustia e solidão, amor e solicitude, é um doar-se ao outro, um exercício de complacência e alteridade.

\section{Literatura}

Adelman M., 2007, Modernidade e pós-modernidade em vozes femininas, in: Codato A., org., "Para Viver no Século XXI. Os Problemas da Contemporaneidade". 
Adelman M., 2009, A voz e a escuta: encontros e desencontros entre a teoria feminista e a sociologia contemporânea, São Paulo.

Barros D. Paes de, 2004, Fast Cars and Bad Girls: Nomadic Subjects and Women's Road Stories. (Travel Writing Across the Disciplines), New York.

Beavouir S. de, 1980, O segundo sexo, São Paulo.

Butler J., 1987, Feminismo como crítica da Modernidade, Rio de Janeiro.

Chute H.L., 2010, Graphic Women - Life Narrative and Contemporary Comics, New York.

Felski R., 1995, The Gender of Modernity, Cambridge.

García S., 2012, A novela gráfica, São Paulo.

Knisley L., 2017, Deslocamento: Um diário de Viagem, São Paulo.

Serrano S., 2014, Mulheres Viajantes, Lisboa.

Valter do Carmo Moreira - Licenciado em Artes Visuais pela Universidade Estadual de Londrina (2014), Especialista em Literatura Brasileira (2015) e Mestre em Literatura Comparada (2018) pela mesma instituição. Atualmente é Doutorando do programa de Pós-graduação em Estudos Literários da Universidade Federal do Paraná. É professor, pesquisador e autor de histórias em quadrinhos, e também artista plástico. Desde a graduação desenvolve pesquisas voltadas ao estudo das histórias em quadrinhos e suas relações com a Literatura e as Artes Visuais. Também investiga as questões do insólito na literatura e, sobretudo, na obra de Franz Kafka. Docente na Universidade Estadual de Londrina, leciona nos cursos de Artes Visuais, Moda e Letras Francês. Também é docente na Universidade Norte do Paraná e Anhanguera, lecionando nos cursos de Artes Visuais, Formação Pedagógica em Artes e Arquitetura e Urbanismo. Autor do Livro: Batman e o Surrealismo: estratégias poéticas surrealistas dentro do Asilo Arkham (2019), também colabora ativamente em diversos periódicos, sendo o seu mais recente artigo publicado: Figurações do estrangeiro em: Na colônia penal de Franz Kafka (2020). Como autor de quadrinhos, publica seu trabalho de forma independente, sendo seu último título lançando: Viveiro (2018).

e-mail: valter.chimba@gmail.com 